\title{
Patterns, Perception and Behavior of Electronic Nicotine Delivery Systems Use and Multiple Product Use Among Young Adults
}

\author{
Mary P Martinasek PhD RRT CPH MPH, Amy Bowersock PhD, and \\ Christopher W Wheldon PhD
}

\begin{abstract}
BACKGROUND: Electronic nicotine delivery systems (ENDS) are battery-operated devices used to inhale vaporized or aerosolized nicotine. There is increasing research uncovering negative health effects of these devices. Less is known about the social and behavioral aspects among college students. METHODS: This cross-sectional study was conducted at a mid-sized private university in Florida. The survey was sent via e-mail to the student body of undergraduates. A final sample size of 989 students was analyzed to understand demographic differences between users and nonusers, initiation factors, and influencers, as well as multiple product behaviors. RESULTS: Approximately 51.4\% $(n=508)$ of participants reported ever using an ENDS and other tobacco consumption. Males were significantly more likely to be users of ENDS. Polytobacco use, or the use of multiple tobacco products, was also more common among participants who have tried ENDS $(P<.001)$. Perceptions of harm of both the primary and secondary vapor were considered to be less than that of conventional cigarettes. Peers were the primary influencer for initial use. A 4-class latent variable model differentiated between usage patterns characterized as abstainers (70\%), hookah users only (14\%), ENDS only (11\%), and polytobacco users (4\%). CONCLUSIONS: ENDS are not commonly used as a quit tool among college students, but rather as a secondary source of nicotine, most commonly in current smokers. Key words: electronic cigarettes; ENDS; e-cigarettes; young adults; college students. [Respir Care 2018;63(7):913-919. (C) 2018 Daedalus Enterprises]
\end{abstract}

\section{Introduction}

Electronic nicotine delivery systems (ENDS) are noncombustible, non-tobacco, flavored products that primarily contain liquid nicotine, but also contain propylene glycol and glycerin as propellants. ${ }^{1,2}$ Advocates of ENDS usage cite a therapeutic benefit as a titration aid for cigarette smoking cessation. Statistics suggest an increase in

Drs Martinasek and Bowersock are affiliated with the Department of Health Sciences and Human Performance, University of Tampa, Tampa, Florida. Dr Wheldon is affiliated with the Division of Cancer Control and Population Sciences, National Cancer Institute, Bethesda, Maryland.

The authors have disclosed no conflicts of interest.

Correspondence: Mary Martinasek PhD RRT CPH MPH, Department of Health Sciences and Human Performance, University of Tampa, 401 W Kennedy Boulevard, Box 30F, Tampa, FL 33606. E-mail: mmartinasek@ut.edu.

DOI: $10.4187 /$ respcare. 06001 dual users (cigarette smokers who also use ENDS) as well as in initial users since $2011 .^{3}$ The U.S. Centers for Disease Control and Prevention report, based on the National Adult Tobacco Survey, indicated that the prevalence of ENDS ever- and current use of ENDS in those age $18-24$ years of age was $35.8 \%$ and $13.6 \%$, respectively. ${ }^{4}$ The National Health Interview Survey has been collecting data regarding ENDS use since 2014; their findings state that the $18-24$ years of age cohort is the highest in ever-use and in "every day or some days" use, and ranks second only to non-Hispanic American Indians/African Natives in current use. ${ }^{5,6}$ Since its issuance in 2016, the U.S. Food and Drug Administration deeming rule brings ENDS under their purview for forthcoming regulations. ${ }^{7}$ These regulations fall in the wake of the increasing prevalence of ENDS use among all populations, but most prominently youth and young adults.

Increasing research is uncovering negative health effects of ENDS products. It is known that the addictive substance, nicotine, poses negative consequences to youth and young adults. ${ }^{4}$ Harm due to nicotine exposure and toxicity are real 
concerns. Nicotine content varies across available cartridges and refill solutions. ${ }^{8}{ }^{8}$ Furthermore, user practice influences the quantity of nicotine delivered in a single puff. ${ }^{10}$ The higher the concentration of nicotine delivery, the greater the likelihood of addiction. This variability of nicotine makes it especially difficult to determine exposure risks. However, nicotine exposure through the various routes (mucosal, inhalation, transdermal, and gastrointestinal) have resulted in symptoms such as dizziness, nausea, emesis, and eye and airway irritation. ${ }^{11-13}$

Additional case report data have indicated negative respiratory effects, oropharyngeal damage, cardiovascular effects, suicide, and poisonings. ${ }^{14,15}$ Associations have been made between ENDS use and depressive symptoms in adolescents and young adults. ${ }^{16,17}$ Findings related to respiratory irritants and carcinogens in the aerosols of ENDS are being identified in various brands and types of ENDS. For example, volatile aldehydes, formalin, diacetyl, and heavy metals such as tin, silver, iron, and nickel have been identified. ${ }^{18-21}$

The health risks of ENDS are not limited to users, as non-users risk secondary and tertiary exposure. Secondary exposure to secondhand or environmental vapor risks include air contamination and potential inhalation of aluminum, nicotine, glycerine, and polyaromatic hydrocarbons. ${ }^{11,22}$ Tertiary exposure to aerosolized nicotine and to traces of nicotine can occur on fomites. ${ }^{23}$ When nicotine mixes with nitrous acid manufactured by household and commercial appliances, tobacco-specific nitrosamines are produced. Tobacco-specific nitrosamines are known carcinogens, and exposure may occur via ingestion, inhalation, or transdermally. Although less is known about tertiary exposure from ENDS, evidence is mounting regarding exposure from conventional cigarettes. ${ }^{23-25}$

Laypeople ascribe low risk to ENDS use, especially when compared to both combustible and smokeless tobacco products. In a sample of college students classified as ever-smokers, $45 \%$ believed that ENDS were safer than combustible cigarettes. ${ }^{26}$ Our study was multifaceted in nature. We explored the perception of harm from both firsthand and secondhand vapor. We explored college students' patterns of use, especially differences between ENDS users and nonusers, and the particulars of initial use. Finally, we conducted a latent class analysis to further uncover the multidimensional nature of tobacco product and marijuana use.

\section{Methods}

\section{Participants and Procedures}

We developed a cross-sectional survey to assess ENDS use at a mid-sized, independent, liberal arts university in Florida. Situated in downtown Tampa, the University of Tampa is a residential university with a student population

\section{QUICK LOOK}

\section{Current knowledge}

Young adults partake in novel smoking behaviors experimentally and with little knowledge of the health effects. Those who currently smoke other products are more likely to try electronic cigarettes.

\section{What this paper contributes to our knowledge}

Electronic nicotine delivery system users are often influenced by peers to vape. There were negative physiological effects such as coughing and throat burning associated with this smoking behavior.

of around 10,000 undergraduate and graduate students. E-mail addresses were obtained from the university's Office of Institutional Effectiveness. The survey was sent via e-mail invitation by the primary investigator, and participation was voluntary.

Consent for the study was achieved by describing the study in the recruitment e-mail. If participants voluntarily agreed to participate in the study, they were requested to click on an external link that directed them to the online survey using Google forms. The recruitment e-mail for this survey was sent to all undergraduate students attending the University of Tampa in the fall of 2016. Both ENDS users and non-users were invited to complete the survey.

Data were collected for 1 week during the fall semester to avoid holidays and summer days. Incentives to participate included a drawing for one of ten $\$ 50$ gift cards. Participants' e-mail addresses were numbered upon completion of the survey, and a drawing using a randomnumber generator was utilized to distribute the gift cards. The survey instrument was designed by the first and second authors. Inclusion criteria were current enrollment at the University of Tampa and age $\geq 17 \mathrm{y}$.

Students were excluded if they did not respond to the honesty question at the end of the survey, which asked, "Were you honest in your responses?" Nineteen duplicate e-mail addresses resulted in additional exclusions. This study was approved by the Institutional Review Board at the University prior to study commencement. Survey data were kept on a password-protected computer.

\section{Analysis}

All statistical analyses were conducted with SAS 9.4. A total of 994 participants initiated the survey and met inclusion criteria. Of these, 5 did not respond to the 
Table 1. Characteristics of ENDS Users and Non-Users

\begin{tabular}{|c|c|c|c|c|}
\hline Survey Questions & Non-Users, $n(\%)$ & Users, $n(\%)^{*}$ & Total, $n(\%)$ & $P$ \\
\hline \multicolumn{5}{|l|}{ Gender } \\
\hline Male & $109(35.3)$ & $200(64.7)$ & $309(31.3)$ & $<.001$ \\
\hline Female & $366(54.7)$ & $303(45.3)$ & $669(67.7)$ & \\
\hline Transgender/gender non-conforming & $5(50.0)$ & $5(50.0)$ & $10(1.0)$ & \\
\hline Age, y & & & & .18 \\
\hline 18 & $185(52.4)$ & $168(47.6)$ & $353(36.2)$ & \\
\hline 19 & $98(44.1)$ & $124(55.9)$ & $222(22.8)$ & \\
\hline 20 & $63(47.4)$ & $70(52.6)$ & $133(13.7)$ & \\
\hline 21 & $64(43.2)$ & $84(56.8)$ & $148(15.2)$ & \\
\hline 22 & $30(57.7)$ & $22(42.3)$ & $52(5.3)$ & \\
\hline 23 or older & $34(51.5)$ & $32(48.5)$ & $66(6.8)$ & \\
\hline Race & & & & .34 \\
\hline White & $341(48.1)$ & $368(51.9)$ & 709 (72.4) & \\
\hline Black & $25(46.3)$ & $29(53.7)$ & $54(5.5)$ & \\
\hline Hispanic & $49(45.8)$ & $58(54.2)$ & $107(10.9)$ & \\
\hline Asian/Pacific Islander & $23(60.5)$ & $15(39.5)$ & $38(3.9)$ & \\
\hline Multi-ethnic & $21(46.7)$ & $24(53.3)$ & $45(4.6)$ & \\
\hline Other & $17(65.4)$ & $9(34.6)$ & $26(2.7)$ & \\
\hline Sexual identity & & & & .14 \\
\hline Heterosexual & $440(49.5)$ & $449(50.5)$ & 889 (91.9) & \\
\hline Gay or lesbian & $9(33.3)$ & $18(66.7)$ & $27(2.8)$ & \\
\hline Bisexual & $21(41.2)$ & $30(58.8)$ & $51(5.3)$ & \\
\hline Respiratory health & & & & .46 \\
\hline History of asthma & $91(51.5)$ & 87 (48.9) & $178(18.0)$ & \\
\hline No history of asthma & $390(48.1)$ & $421(51.9)$ & $811(82.0)$ & \\
\hline Perceptions of harm from use & & & & $<.001$ \\
\hline Less harmful than cigarettes & $139(31.5)$ & $303(68.6)$ & $442(44.8)$ & \\
\hline Equally as harmful & $253(64.2)$ & $141(35.8)$ & 394 (39.9) & \\
\hline More harmful & $45(69.2)$ & $20(30.8)$ & $65(6.6)$ & \\
\hline Do not know & $44(51.2)$ & $42(48.8)$ & $86(8.7)$ & \\
\hline Perception of secondhand effects & & & & $<.001$ \\
\hline It is safe for others to be around & $56(22.2)$ & $196(77.8)$ & $252(25.6)$ & \\
\hline It is unsafe for others & $251(69.9)$ & $108(30.1)$ & $359(36.4)$ & \\
\hline Do not know & $173(46.1)$ & $202(53.9)$ & 375 (38.0) & \\
\hline
\end{tabular}

ENDS use question and were removed from further analyses. The analytic sample was 989 participants. Item-level missing data were $<5 \%$, so list-wise deletion was used in bivariate comparisons.

Differences in sample characteristics, risk perceptions, and tobacco use between ENDS users and non-users were compared using chi-square analysis. Latent class analysis was used to explore the multidimensional nature of tobacco product and marijuana use. The likelihood ratio chi-square test, the Akaike information criterion, and the Bayesian information criterion were used to examine model fit along with the interpretability of 1-5 latent classes. A 4-class model was selected, interpreted (ie, classes were given descriptive labels), and used to examine latent class prevalence.

\section{Results}

Demographic characteristics of the study sample are reported in Table 1. The sample was mostly female (67.7\%), non-Hispanic white (72.4\%), and heterosexual (91.9\%). Nearly three quarters $(72.7 \%)$ of users were $18-20$ y old.

Approximately 51.4\% $(n=508)$ of subjects reported ever using an ENDS product. ENDS users were most likely to be male, to perceive e-cigarettes as less harmful than traditional cigarettes, and to perceive ENDS to pose fewer secondhand effects $(P<.001)$.

Comparisons of current tobacco use behaviors among ENDS device users and non-users are reported in Table 2. 


\section{Behavioral Aspects of ENDS Use in Young Adults}

Table 2. Comparison of Tobacco Use Behaviors Among Electronic Device Users and Non-Users

\begin{tabular}{lccc}
\hline \hline Survey Questions & Non-Users, $n(\%)$ & Users, $n(\%) *$ & Total, $n(\%)$ \\
\hline Number of products used & & & $P$ \\
0 & $443(62.6)$ & $265(37.4)$ & $708(71.6)$ \\
1 & $30(16.0)$ & $157(84.0)$ & $187(18.9)$ \\
2 & $6(11.1)$ & $48(88.9)$ & $54(5.5)$ \\
3 or more & $2(5.00)$ & $38(95.0)$ & $40(4.0)$ \\
Currently use cigarettes & $6(7.7)$ & $72(92.3)$ & $78(7.9)$ \\
$\quad$ Yes & $475(52.1)$ & $436(47.9)$ & $911(92.1)$ \\
No & $8(12.7)$ & $55(87.3)$ & $63(6.4)$ \\
Currently use cigars & $473(51.1)$ & $453(48.9)$ & $926(93.6)$ \\
$\quad$ Yes & $1(2.7)$ & $36(97.3)$ & $37(3.7)$ \\
No & $480(50.4)$ & $472(49.6)$ & $952(96.3)$ \\
Currently use cigarillos & $6(6.4)$ & $88(93.6)$ & $<.001$ \\
Yes & $475(53.1)$ & $420(46.9)$ & $94(9.5)$ \\
No & & & $895(90.5)$ \\
Currently use hookah & $27(17.1)$ & $131(82.9)$ & $158(16.0)$ \\
$\quad$ Yes & $454(54.6)$ & $377(45.4)$ & $831(84.0)$
\end{tabular}

$N=1,014$ subjects, with 497 (49.0\%) non-users and 517 (51.0\%) smoking device users.

* Users are defined as those who have ever used electronic smoking devices.

Polytobacco use, or the use of multiple tobacco products, was more common among subjects who have tried ENDS $(P<.001)$. Trying ENDS was very common among current users of cigarettes, cigars, cigarillos, hookah, and marijuana $(P<.001)$; $97.3 \%$ of cigarillo users, $93.6 \%$ of hookah users, $92.3 \%$ of cigarette users, $87.3 \%$ of cigar users, and $82.9 \%$ of marijuana users have at least tried ENDS.

Smokers were assessed with regard to how often they vaped, the type of device they used, and the location of vaping (Table 3). Among those who have tried an ENDS, 35.1\% vaped from an electronic device within the past $30 \mathrm{~d}$, and $17 \%$ smoked at least once a day. Approximately a quarter $(26.1 \%)$ of ENDS users have been using them for a year or longer. The majority of the subjects used a rechargeable device $(70.0 \%)$ and smoked in multiple locations. ENDS use at bars or clubs was common $(23.6 \%)$, as was smoking while consuming alcoholic beverages $(26.2 \%)$.

Reasons, influencers, and physiological experiences were evaluated (Table 4). The most commonly reported reason for initiating ENDS use was peer influence (36.9\%). Most did not experience any negative effects during initial use $(56.3 \%)$; however, some reported coughing (19.7\%), throat burn (10.8\%), and headache (7.1\%).

Four latent classes were selected based on the likelihood ratio chi-square test, Akaike information criterion, Bayes- ian information criterion, and interpretability (see Table 5). Current use of 5 tobacco products and marijuana were examined (ENDS, cigarette, cigar, cigarillo, hookah, and marijuana). Use of each product was considered a part of the class membership if item-response probabilities were $\geq 0.40$ as noted in Table 6 . The 4 -class model differentiated between usage categories that we labeled as Abstainers $(70 \%)$, Hookah users only (14\%), ENDS users only (11\%), and Poly tobacco users (4\%). Percentages in parentheses represent the distribution of our sample according to class membership.

\section{Discussion}

This exploratory, descriptive study sought to understand intricacies about ENDS users. We found that using ENDS to quit smoking regular cigarettes was reported by a minority of subjects, despite being advertised as a quit aid. Our study found that concurrent use of cigarettes and ENDS was common. More non-users felt that the primary vape effects were more harmful than the effects of secondhand vape. This could be because the vapor dissipates faster than smoke when exhaled from the smoker's mouth, resulting in less secondhand vapor and thus a weaker effect. There is a dearth of literature on the effects of secondhand vapor, so understanding perceptions is valuable to add to the body of knowledge. ${ }^{22}$ 
Table 3. Patterns of Use Among ENDS Users

\begin{tabular}{lc}
\hline \multicolumn{1}{c}{ Survey Questions } & $n(\%)$ \\
\hline Use in the past $30 \mathrm{~d}(n=507)$ & $178(35.1)$ \\
Frequency of Daily Use $(n=507)$ & \\
Not used everyday & $421(83.0)$ \\
1 to 5 times & $26(5.1)$ \\
6 to 10 times & $13(2.6)$ \\
11 to 19 times & $11(2.2)$ \\
20 or more times & $36(7.1)$ \\
Duration of Use $(n=498)$ & \\
Less than a week & $232(46.6)$ \\
1 week to 1 month & $35(7.0)$ \\
1 to 3 months & $45(9.0)$ \\
6 months to 1 year & $56(11.2)$ \\
Over one year & $130(26.1)$ \\
Type of device used most frequently $(n=493)$ & \\
Rechargeable & $345(70.0)$ \\
Disposable & $105(21.3)$ \\
Both & $43(8.7)$ \\
Place where typically smoke $(n=508)^{*}$ & \\
Everywhere it is allowed & $96(18.9)$ \\
Work & $15(3.0)$ \\
Home & $181(35.6)$ \\
Car & $89(17.5)$ \\
Restaurant & $8(1.6)$ \\
Outside & $148(29.1)$ \\
Class & $4(1.0)$ \\
At bars or clubs & $120(23.6)$ \\
When most routinely smokes from electronic & \\
$\quad$ After a meal $(n=481)$ & \\
With alcoholic beverages & $16(3.3)$ \\
When stressed & \\
First thing in the morning & \\
Whenever I can & \\
Other & \\
\hline
\end{tabular}

The latent classes identified are consistent with previous research in this college population. The largest group were abstainers, followed by subjects who were most likely experimenting with tobacco products like Reflections on Initial ENDS Use and hookah in social situations. Hookah use was very common in this college population, and we found that a majority of hookah users were also trying ENDS. ${ }^{27}$ A smaller subset of users were using only ENDS. This could indicate that ENDS are a gateway to tobacco product use, or that they are used as replacements or substitutions for other types of tobacco products. While we could not test these hypotheses directly in this study, examination of the primary reasons for ENDS initiation suggest that the appeal of ENDS is not to serve as a replacement for other products, at least in this college sample of young adults. Previous studies support the initiation into
Table 4. Reflections on Initial ENDS Use

\begin{tabular}{lc}
\hline \multicolumn{1}{c}{ Survey Questions ( $n$ Respondents) } & $n(\%)$ \\
\hline Primary reason to smoke the first time $(n=504)$ & \\
Trying to quit smoking regular cigarettes & $43(8.5)$ \\
Friends smoking & $186(36.9)$ \\
Looks cool & $45(8.9)$ \\
I smoke other products and wanted to try it & $47(9.3)$ \\
To lose weight & $3(1.0)$ \\
To enjoy the flavors that I love in food & $40(7.9)$ \\
To relieve stress & $76(15.1)$ \\
Weight management & $1(<1)$ \\
Other & $63(12.5)$ \\
Who or what influenced to try $(n=505)$ & \\
Friend who smokes one & $339(67.1)$ \\
Family member & $17(3.4)$ \\
Advertisement & $10(2.0)$ \\
Teacher & $2(<1)$ \\
No one & $108(21.4)$ \\
Other & $29(5.7)$ \\
Experience during initial use $(n=508)$ & \\
Headache & $36(7.1)$ \\
Throat burned & $55(10.8)$ \\
Stomach ache & $10(2.0)$ \\
Sinus issues & $4(1.0)$ \\
Coughing & $100(19.7)$ \\
Lungs hurt & $4(1.0)$ \\
I did not experience any bad effects & $286(56.3)$ \\
Other & $13(2.6)$ \\
\hline
\end{tabular}

Table 5. Fit Statistics for LCA Models of Current Tobacco Product and Marijuana Use With 1-5 Latent Classes

\begin{tabular}{lcccc}
\hline \hline $\begin{array}{c}\text { Number of } \\
\text { Classes }\end{array}$ & $\begin{array}{c}\text { Likelihood Ratio } \\
\text { Chi-Square } \\
\text { Test }\end{array}$ & $\begin{array}{c}\text { Akaike } \\
\text { Information } \\
\text { Criterion }\end{array}$ & $\begin{array}{c}\text { Bayesian } \\
\text { Information } \\
\text { Criterion }\end{array}$ & Entropy \\
\hline 1 & 332.54 & 342.54 & 367.05 & 1.00 \\
2 & 49.08 & 71.08 & 125.00 & 0.69 \\
3 & 38.97 & 72.97 & 156.30 & 0.57 \\
$\mathbf{4}$ & $\mathbf{2 0 . 9 2}$ & $\mathbf{6 6 . 9 2}$ & $\mathbf{1 7 9 . 6 6}$ & $\mathbf{0 . 7 4}$ \\
5 & 15.81 & 73.81 & 215.96 & 0.67
\end{tabular}

Bold text indicates the best-fitting model.

$\mathrm{LCA}=$ latent class analysis

ENDS use as a gateway to the use of combustible cigarettes in similar age cohorts. ${ }^{28,29}$

Results indicated demographic differences, with ENDS users being predominantly male compared to non-users. Most subjects who have used an ENDS do not use it every day and have used it for $<1$ week. This may indicate that more ENDS users are experimenters as opposed to continuous users. Cost is not a barrier in this sample, as most subjects reported purchasing the rechargeable units. This could indicate the desire for a device that does not look like a cigarette-shaped device. Smoking cigarettes at home 


\section{Behavioral Aspects of ENDS Use in Young Adults}

Table 6. Item Response Probabilities for 3, 4, and 5 Classes

\begin{tabular}{|c|c|c|c|c|c|c|c|c|c|c|c|c|}
\hline & \multicolumn{3}{|c|}{3 Classes } & \multicolumn{4}{|c|}{4 Classes $^{\mathrm{a}}$} & \multicolumn{5}{|c|}{5 Classes } \\
\hline & 1 & 2 & 3 & 1 & 2 & 3 & 4 & 1 & 2 & 3 & 4 & 5 \\
\hline ENDS & 0.28 & 0.79 & 0.03 & 0.29 & 0.72 & 0.92 & 0.00 & 0.44 & 0.68 & 0.95 & 0.01 & 0.36 \\
\hline Cigarette & 0.16 & 0.34 & 0.01 & 0.17 & 0.57 & 0.18 & 0.01 & 0.39 & 0.66 & 0.07 & 0.00 & 0.03 \\
\hline Cigar & 0.01 & 0.37 & 0.03 & 0.01 & 0.48 & 0.20 & 0.03 & 0.00 & 0.46 & 0.51 & 0.03 & 0.00 \\
\hline Hookah & 0.24 & 0.33 & 0.01 & 0.42 & 0.70 & 0.02 & 0.00 & 0.19 & 0.64 & 0.05 & 0.01 & 0.23 \\
\hline Marijuana & 0.26 & 0.53 & 0.06 & 0.28 & 0.77 & 0.30 & 0.07 & 0.04 & 0.77 & 0.33 & 0.04 & 0.50 \\
\hline
\end{tabular}

${ }^{a}$ The 4-class model differentiated between usage categories as follows: Class 1 (Hookah users only), Class 2 (Poly users), Class 3 (ENDS users only), Class 4 (Abstainers)

ENDS = electronic nicotine delivery systems

and outside were most popular in conjunction with vaping and drinking.

This study was limited to data collected from one university, so the findings may differ in other geographic regions or universities. The study did not explore people who do not attend college. The data collected were self-reported and from a single university in Florida, so the results may not be generalizable to other institutions. However, in previous tobaccorelated studies, we have found the characteristics to be similar between two colleges in the same town. The large sample size provided robust power to the study. The study explored many aspects that fill gaps in the literature and add previously unreported details to the body of knowledge on ENDS use among young adults. In particular, polytobacco use among users and non-users indicated that users of ENDS had a greater propensity to smoke other tobacco products, including marijuana.

\section{Conclusions}

This study helps uncover reasons for initiation of vaping in a college student population as well as information to inform health messaging in hospitals and among respiratory therapists in community settings. This formative research can lead to the development of social marketing campaigns to educate college students in making informed decisions about their choice to vape and provides the university with information on multiple product usage. Additionally, this study emphasizes the importance of sharing the negative health effects of ENDS use. Future research should seek to determine whether vaping and alcohol consumption are co-occurrences similar to traditional smoking and alcohol consumption. Future research should also consider longitudinal data collection to determine whether ENDS products are a gateway across colleges. Additionally, studies should consider following the progression of nicotine titration or nicotine dose dependence to understand how these products are used to achieve nicotine abstinence in college students.

\section{REFERENCES}

1. Beauval N, Antherieu S, Soyez M, Gengler N, Grova N, Howsam M, et al. Chemical evaluation of electronic cigarettes: Multicomponent analysis of liquid refills and their corresponding aerosols. J Anal Toxicol 2017;1-9.

2. Hutzler C, Paschke M, Kruschinski S, Henkler F, Hahn J, Luch A. Chemical hazards present in liquids and vapors of electronic cigarettes. Arch Toxicol 2014;88(7):1295-1308.

3. King BA, Patel R, Nguyen KH, Dube SR. Trends in awareness and use of electronic cigarettes among US adults, 2010-2013. Nicotine Tobacco Res 2014;17(2):219-227.

4. Murthy V. E-cigarette use among youth and young adults: a report of the surgeon general. Rockville, MD: U.S. Department of Health and Human Services; 2016.

5. Schoenborn C, Gindi RM. Electronic cigarette use among adults: United States, 2014. https://www.cdc.gov/nchs/products/databriefs/ db217.htm. Accessed February 21, 2018.

6. Weaver SR, Majeed BA, Pechacek TF, Nyman AL, Gregory KR, Eriksen MP. Use of electronic nicotine delivery systems and other tobacco products among USA adults, 2014: results from a national survey. Int J Public Health 2016;61(2):177-188.

7. U.S. Food and Drug Administration. Vaporizers, E-Cigarettes, and other Electronic Nicotine Delivery Systems (ENDS). http://www. fda.gov/TobaccoProducts/Labeling/ProductsIngredientsComponents/ ucm456610.htm. Accessed February 21, 2018.

8. Baassiri M, Talih S, Salman R, Karaoghlanian N, Saleh R, El Hage $\mathrm{R}$, et al. Clouds and "throat hit": effects of liquid composition on nicotine emissions and physical characteristics of electronic cigarette aerosols. Aerosol Sci Technol. 2017 [Epub ahead of print] doi: 10.1080/02786826.2017.1341040.

9. Lee M, LeBouf RF, Son Y, Koutrakis P, Christiani DC. Nicotine, aerosol particles, carbonyls and volatile organic compounds in tobacco-and menthol-flavored e-cigarettes. Environ Health 2017;16(1):42.

10. Schroeder MJ, Hoffman AC. Electronic cigarettes and nicotine clinical pharmacology. Tob Control 2014;23(Suppl 2):ii30-ii35.

11. Cantrell FL. Adverse effects of e-cigarette exposures. J Community Health 2014;39(3):614-616.

12. Chatham-Stephens K, Law R, Taylor E, Melstrom P, Bunnell R, Wang $\mathrm{B}$, et al. Notes from the field: calls to poison centers for exposures to electronic cigarettes-United States, September 2010-February 2014. MMWR Morb Mortal Wkly Rep 2014;63(13):292-293.

13. Meo S, Al Asiri S. Effects of electronic cigarette smoking on human health. Eur Rev Med Pharmacol Sci 2014;18(21):3315-3319.

14. Welz C, Canis M, Schwenk-Zieger S, Becker S, Stucke V, Ihler F, Baumeister P. Cytotoxic and genotoxic effects of electronic cigarette liquids on human mucosal tissue cultures of the oropharynx. J Environ Pathol Toxicol Oncol 2016;35(4):343-354. 


\section{Behavioral Aspects of ENDS Use in Young Adults}

15. Talbot P. Potential health effects of electronic cigarettes: A systematic review of case reports. Prev Med Rep 2016;4:169-178.

16. Bandiera FC, Caban-Martinez AJ, Arheart KL, Davila EP, Fleming LE, Dietz NA, et al. Secondhand smoke policy and the risk of depression. Ann Behav Med 2010;39(2):198-203.

17. Lechner WV, Janssen T, Kahler CW, Audrain-McGovern J, Leventhal AM. Bi-directional associations of electronic and combustible cigarette use onset patterns with depressive symptoms in adolescents. Prev Med 2017;96:73-78.

18. Allen JG, Flanigan SS, LeBlanc M, Vallarino J, MacNaughton P, Stewart JH, Christiani DC. Flavoring chemicals in e-cigarettes: diacetyl, 2,3-pentanedione, and acetoin in a sample of 51 products, including fruit-, candy-, and cocktail-flavored e-cigarettes. Environ Health Perspect 2016;124(6):733-739.

19. Talih S, Balhas Z, Salman R, Karaoghlanian N, Shihadeh A. "Direct dripping": a high-temperature, high-formaldehyde emission electronic cigarette use method. Nicotine Tobacco Res 2015;18(4):453-459.

20. Tierney PA, Karpinski CD, Brown JE, Luo W, Pankow JF. Flavour chemicals in electronic cigarette fluids. Tob Control 2016;25(e1): e10-e15.

21. Williams M, Villarreal A, Bozhilov K, Lin S, Talbot P. Metal and silicate particles including nanoparticles are present in electronic cigarette cartomizer fluid and aerosol. PloS One 2013;8(3):e57987.

22. Schober W, Szendrei K, Matzen W, et al. Use of electronic cigarettes (e-cigarettes) impairs indoor air quality and increases FeNO levels of e-cigarette consumers. Int J Hyg Environ Health 2014; 217(6):628-637.

23. Goniewicz ML, Lee L. Electronic cigarettes are a source of thirdhand exposure to nicotine. Nicotine Tobacco Res 2014;17(2):256-258.

24. Sleiman M, Gundel LA, Pankow JF, Jacob P 3rd, Singer BC, Destaillats H. Formation of carcinogens indoors by surface-mediated reactions of nicotine with nitrous acid, leading to potential thirdhand smoke hazards. Proc Natl Acad Sci USA 2010;107(15): 6576-6581.

25. Matt GE, Quintana PJ, Destaillats H, et al. Thirdhand tobacco smoke: emerging evidence and arguments for a multidisciplinary research agenda. Environ Health Perspect 2011;119(9):1218-1226.

26. Sutfin EL, McCoy TP, Morrell HE, Hoeppner BB, Wolfson M. Electronic cigarette use by college students. Drug Alcohol Depend 2013;131(3):214-221.

27. Martinasek MP, Haddad LG, Wheldon CW, Barnett TE. Beliefs and attitudes associated with hookah smoking among a United States college population. Respir Care 2017;62(3):370-379.

28. Doran N, Brikmanis K, Petersen A, Delucchi K, Al-Delaimy WK, Luczak S, et al. Does e-cigarette use predict cigarette escalation? A longitudinal study of young adult non-daily smokers. Prev Med 2017; 100:279-284.

29. Primack BA, Soneji S, Stoolmiller M, Fine MJ, Sargent JD. Progression to traditional cigarette smoking after electronic cigarette use among US adolescents and young adults. JAMA Pediatr 2015; 169(11):1018-1023. 